\title{
GIANT HYDATID CYSTS OF THE LUNG
}

Semih Halezeroglu, MD

Muharrem Celik, MD

Aziz Uysal, MD

Canan Senol, MD

Murat Keles, MD

Bulent Arman, MD
Background: Hydatid disease is a parasitic infection caused by Echinococcus granulosus, characterized by cystic lesions in the liver, lungs, and, rarely, in other parts of the body. The large cysts in the lung are a special clinical entity called giant hydatid cysts. Characteristics on presentation, operative techniques, and postoperative morbidity and mortality rates in 47 patients with 50 giant pulmonary hydatid cysts $10 \mathrm{~cm}$ in diameter or larger were reported in this study. Methods: Cystotomy plus the obliteration of the residual cavity by imbricating sutures from within (capitonnage) was the most frequently used operative technique $(n=31)$, followed by pericystectomy plus capitonnage $(n=6)$, closure of bronchial openings plus pericystectomy $(n=6)$, and lobectomy $(n=3)$. Results: The mean age of patients with giant hydatid cyst of the lung was lower than the age of those with usual-sized cysts $(p=0.04)$. Five patients had prolonged air leaks (more than 10 days), three had empyema, and one had pneumonia in the opposite lung after the operation. One patient died of cardiorespiratory collapse during the operation. There was one recurrence during follow-up. Conclusions: The increase in the diameter of the cyst in younger ages was correlated with higher lung tissue elasticity and the delay in diagnosis because of delayed symptoms in these patients. Although postoperative complications occurred in $19.1 \%$ of patients, all were managed by conservative measures, and there were no indications that the affected lung should have been treated with resection instead of a parenchyma-saving operation. (J Thorac Cardiovasc Surg 1997;113:712-7)
$T^{\mathrm{n}}$ he most common sites of lodgment of Echinococcus granulosus are the liver and the lung. Growth rate of the parasite changes with the host's sensitization degree and tissue influence. ${ }^{1,2}$ In the liver, the compact tissue and the hepatobiliary capsules limit the cyst's growth, ${ }^{2}$ and low resistance of lung tissue provides an excellent medium for rapid growth of hydatid cysts. However, the patient's immune response to the parasite and early symptoms during the illness prevent the cyst from growing in an unlimited fashion. Nevertheless, it is not uncommon for a pulmonary hydatid cyst to exist in

From the Heybeliada Chest Disease and Chest Surgery Center, Istanbul, Turkey,

Presented at the Fourth Thoracic Surgery Congress of South America, Punta Del Este, Uruguay, Nov. 11-14, 1995.

Received for publication July 18, 1996; revisions requested Sept. 4, 1996; revisions received Oct. 22, 1996; accepted for publication Nov. 19, 1996.

Address for reprints: Semih Halezeroglu, MD, Kamelya 1-7 Bl. No: 16, Atasehir, 81120 Istanbul, Turkey.

Copyright $(1997$ by Mosby-Year Book, Inc.

$0022-5223 / 97 \$ 5.00+0 \quad \mathbf{1 2 / 1 / 7 9 3 3 9}$ very large sizes and even in multiple numbers. Diagnosis is made by a simple radiologic examination in a patient living (or having lived) in an endemic area. ${ }^{3}$ The goal of surgical therapy is to remove the giant cyst while preserving as much lung tissue as possible.

In this study, we report our 10 years of experience with giant hydatid cysts of the lung.

\section{Patients and methods}

Clinical files of 285 patients who had undergone operations for hydatid disease of the lung in the Heybeliada Chest Disease and Chest Surgery Center from January 1985 to May 1995 were reviewed. Among these patients, 47 (female, 25; male, 22) had 50 hydatid cysts with a diameter of $10 \mathrm{~cm}$ or larger. The mean age of the patients was $24.8 \pm 11.5$ years, ranging from 9 to 65 years. Diameters of the cysts were obtained from the chest $x$-ray films, computed tomographic (CT) scanning, operation notes, or a combination of the three.

Complicated and uncomplicated cysts. The cysts presenting on $\mathrm{x}$-ray films with perforation of the germinative membrane are classified as complicated $(n=27)$. The term complicated did not necessarily indicate an infected cyst. A perforated cyst without infection was also classified 


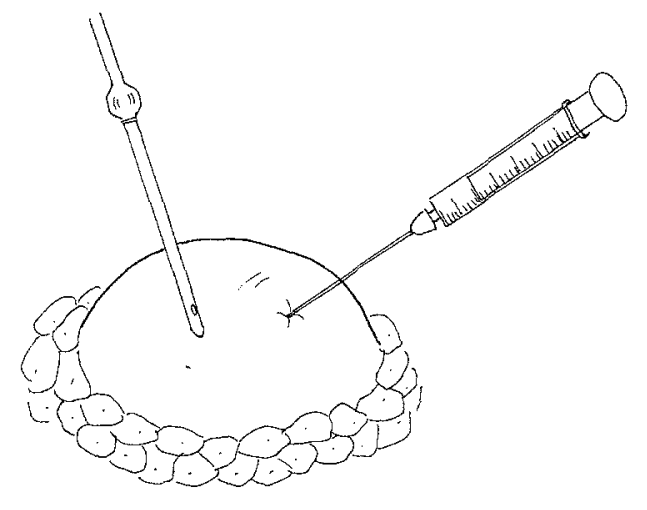

A
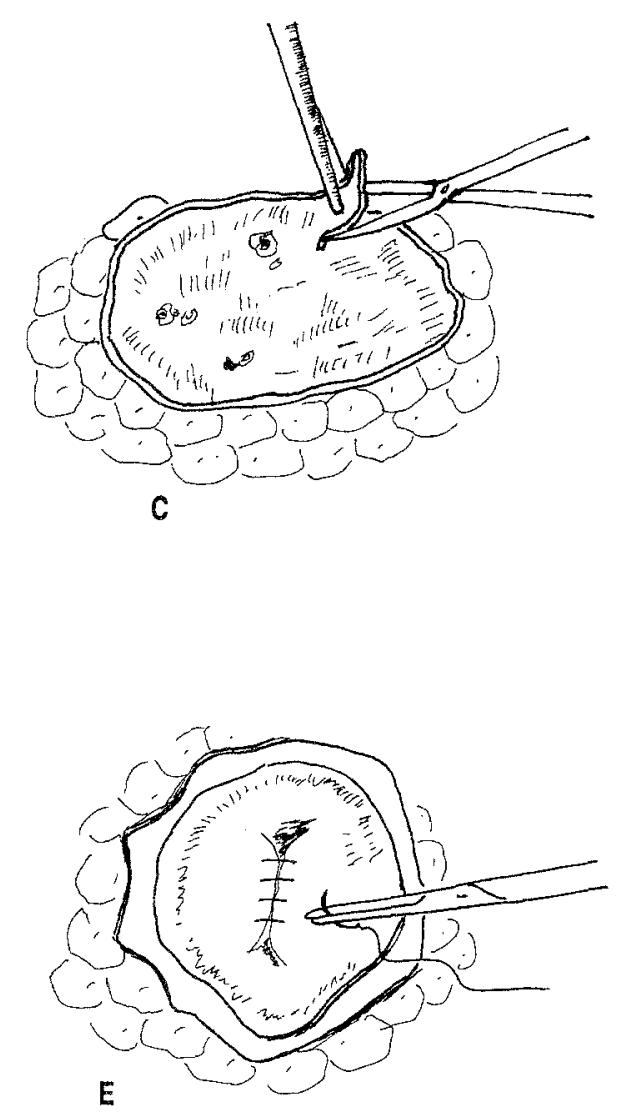
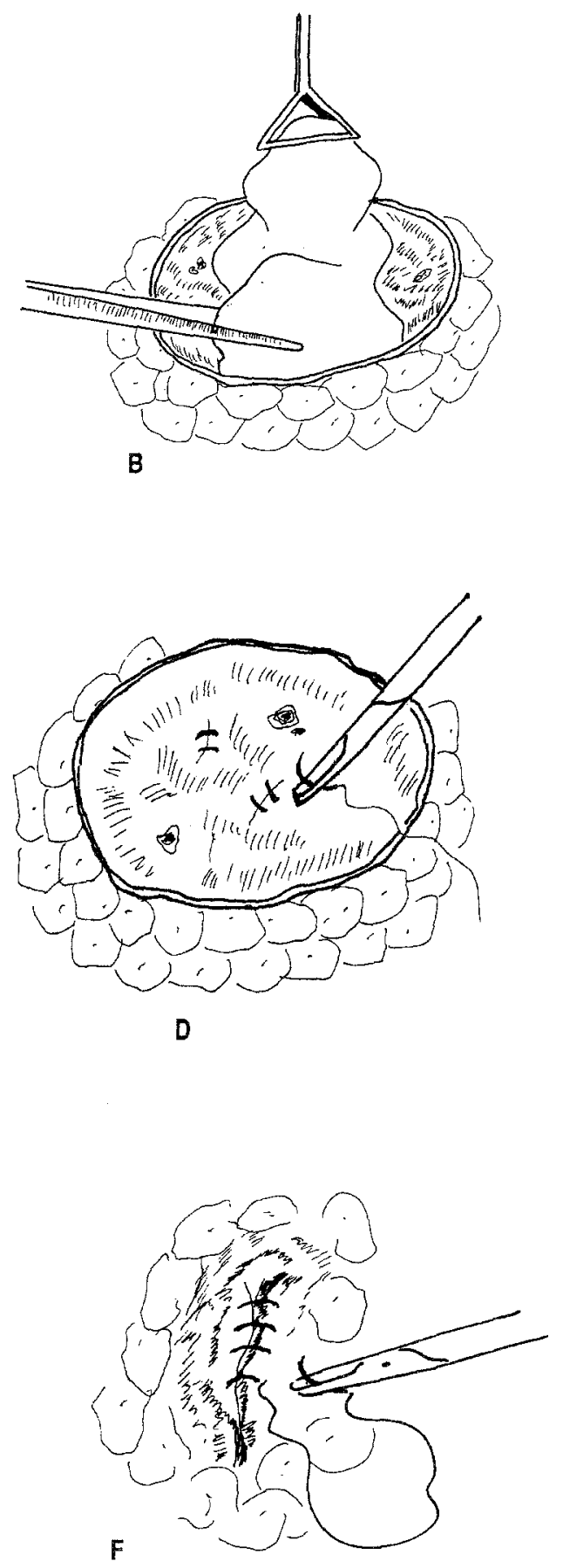

Fig. 1. The removal of a giant hydatid cyst of the lung and the management of residual cavity. An uncomplicated giant cyst is aspirated with a 20-gauge needle (A). The pericyst is opened by a split incision (cystotomy) and germinative membrane removed (B). The pericystic layer can be excised extensively (partial pericystectomy) (C). Bronchial openings are closed (D) by absorbable suture materials. If the cavity remains deep in the lung, imbricating sutures from within are used for obliteration (capitonnage) (E). Then the lesion is covered or not (F) by parenchyma. 
Table I. Age distribution of 47 patients with giant hydatid cyst of the lung

\begin{tabular}{cc} 
Age group $(y r)$ & No. of patients \\
\hline $0-10$ & 3 \\
$11-20$ & 17 \\
$21-30$ & 14 \\
$31-40$ & 6 \\
$>40$ & 7 \\
\hline
\end{tabular}

as complicated. All other cysts with the radiologic findings with an intact germinative membrane were called uncomplicated or intact $(n=23)$.

Chest $\mathrm{x}$-ray films and CT scans of the chest and upper abdomen (in 41 of 47 patients) were performed after a detailed questioning that is critical for the diagnosis. Indirect hemaglutination and Casoni skin tests were also consistently applied. Transthoracic needle aspiration was done in only three patients whose clinical and radiologic data were equivocal. The right and the left lungs had 30 and 20 giant cysts, respectively. Three patients had two cysts in one lobe.

Operative techniques. All procedures were performed while the patient was under general anesthesia with a double-lumen endotracheal tube. Posterolateral thoracotomy through the fifth or sixth intercostal space was accomplished with the patient in the lateral decubitus position.

Uncomplicated giant cysts were mainly removed after needle aspiration $(n=20)$ and enucleation without needle aspiration $(n=3)$. With needle aspiration, hydatid fluid was aspirated first from the uppermost part of the cyst with a 20 -gauge needle to lower the intracystic pressure (Fig. 1, $A$ ). Then a suction apparatus was introduced into the cyst and the fluid was completely aspirated. No scolidical agent was used. In all patients, the needle and suction apparatus insertion site was enlarged by cutting the pericystic layer (host tissue) with scissors or an electrocautery so that the germinative membrane was easily taken out (Fig. 1, B) and the bronchial openings encountered. In the cysts having a small pericystic layer with a deep residual cavity $(n=31)$, this layer was removed only minimally (cystotomy), whereas the ones $(n=12)$ with a large pericystic layer and a superficial residual cavity have undergone extensive resection (partial pericystectomy) (Fig. 1, C).

After removal of the germinative layer, the residual cavity was carefully cleaned and reexplored to look for spillage of daughter vesicles (which is rare for pulmonary hydatid disease). Infected cavities of complicated giant cysts were cleaned by a suction apparatus and irrigated with $1 \%$ povidone-iodine in all patients.

Management of residual cavity. When the cystic cavity was being obliterated, large bronchial openings were closed first with a 3-0 chromic catgut or a 3-0 coated polyglactin 910 (Coated Vicryl, Ethicon, Edinburgh, Scotland) (Fig. 1, D). Then, the cavity was obliterated by imbricating sutures from within (capitonnage) (Fig. $1, E$ ) using the same suture material in $31(66 \%)$ patients. In six $(12.7 \%)$ patients with superficial cysts, the pericystic layer was partially resected before the capitonnage. Only partial pericystectomy without capitonnage was achieved in six $(12.7 \%)$ patients with interlobarly localized cysts. Two right and one left lower lobectomies were performed in three patients $(6.4 \%$ of all and $12.5 \%$ of those with complicated cysts), each having two complicated giant cysts.

\section{Results}

The age distribution indicated that most of the patients (72\%) were in the first three decades of life (Table I). Additionally, the mean age of the patients with giant hydatid cysts was less than the age of the other 238 patients who have been operated on in the same time period for smaller pulmonary hydatid cysts $(24.8 \pm 11.5$ vs $29.7 \pm 10.4, p=0.04, t$ test $)$. On admission, children were surprisingly in better clinical condition than were older patients. The main complaints of young patients were cough and fatigue, but in older patients shortness of breath also occurred. Allergic reactions were not observed in any patient. Hydatoptysis (expectoration of the germinative membrane or the hooklets of the parasite), the only diagnostic symptom of pulmonary hydatid disease, was not observed. However, some patients described a "salty taste in the mouth after vomitlike expectoration of a colorless fluid" that is an important indication of perforated pulmonary hydatid cyst.

Radiologic findings. The most common finding on the chest $\mathrm{x}$-ray film of patients with uncomplicated cysts was a smoothly outlined, dense spherical opacity. Because the hydatid fluid resembles "water" in appearance, CT was helpful in showing the water density in the lesion (Fig. 2). The most prominent radiologic finding of complicated cysts was the presence of an air-fluid level (Fig. 3) or only air between the two layers of the cystic wall. Once the perforation resulted in suppuration, contrast enhancement of the cyst wall and an increase of the fluid density ( $>20$ Hounsfield units) within the cyst were seen on CT.

Results of the indirect hemaglutination and $\mathrm{Ca}$ soni skin tests were found to be positive in 33 $(70.2 \%)$ and $31(66 \%)$ of the patients, respectively. The giant cysts were located most commonly in the right lower lobe $(30 \%)$ and least commonly in the middle lobe $(8 \%)$, as expected.

Morbidity and mortality. Prolonged parenchymal air leak ( $>10$ days) was observed in five patients and was managed by continuous negative aspiration and chest physiotherapy until the lung was fully expanded. All but one of the patients did well with 


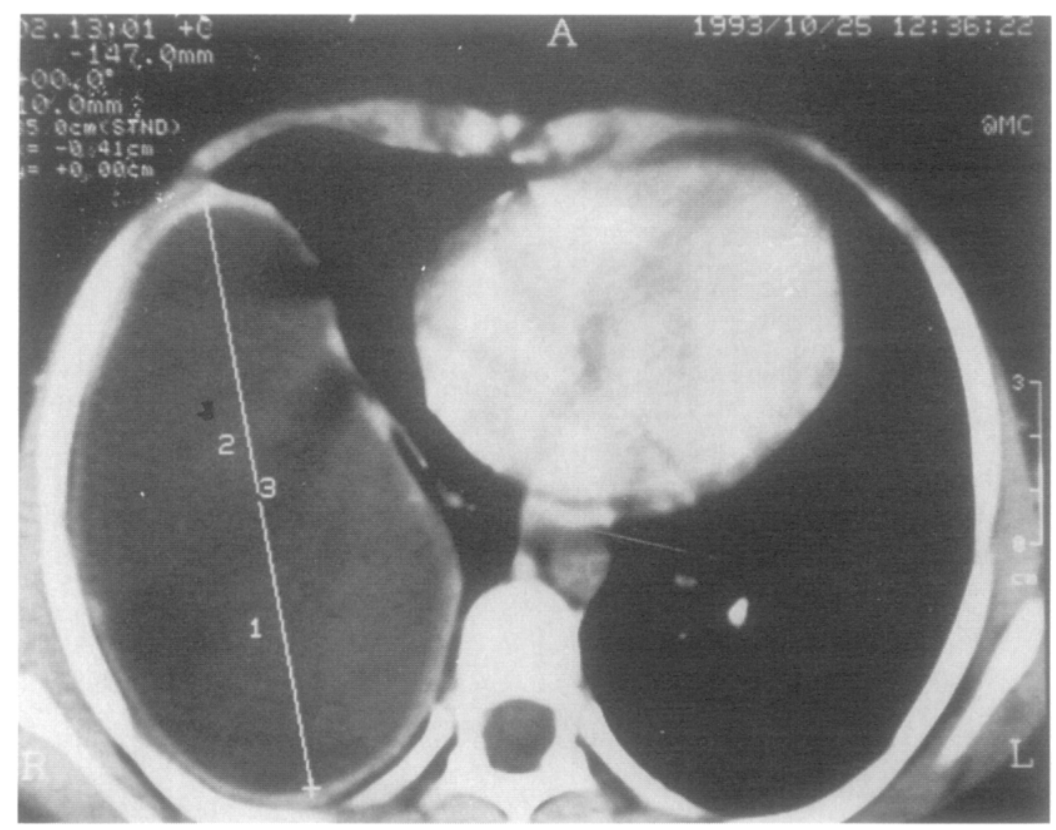

Fig. 2. CT appearance of an uncomplicated giant hydatid cyst of the right lung.

this conservative approach. A new chest tube was needed in one patient who had a hydropneumotho$\operatorname{rax} 2$ days after removal of the chest tube. Pleural empyema $(n=3)$ occurred only in the patients with complicated cysts and was treated by irrigation of the pleural space with isotonic saline solution and parenteral antibiotics. An additional reconstructive intervention was not required for residual pleural thickening. Pneumonia $(n=1)$ in the contralateral lung of a patient with a malfunctioning doublelumen endotracheal tube was considered to be the result of povidone-iodine leakage from the bronchial openings to the main bronchus when the cystic cavity was being cleared. There was no relationship between postoperative complications and operative techniques used (Table II). A 65-year-old patient who had one giant cyst and two small cysts in both lungs died at operation from cardiorespiratory collapse before removal of the cysts was attempted. No deaths occurred in the postoperative period.

Follow-up. Eleven patients were lost to followup. Recurrence was observed in one of 35 patients who was followed up $(2.9 \%)$, with disseminated pleural hydatidosis in the same operative site 4 months after the operation. Recurrence was the result of inadvertent spillage of cystic contents into the pleural space during needle aspiration of the cyst. In another patient, a new occurrence was observed in a different lobe on the same side as the previous operation. Both patients had a second thoracotomy.

\section{Discussion}

Once a hydatid cyst infiltrates the lung, two consequences should be expected: (1) In rare instances, it perforates into a bronchiole and the germinative layer is expectorated. The residual cavity is obliterated spontaneously and the disease subsides. (2) It enlarges in size depending on factors such as location, elasticity of the lung tissue, and the patient's immune response and pulmonary reserve. If these factors combine, the cyst can reach a very large size, namely "giant hydatid cyst."

Immune response to Echinococcus granulosus. The parasite has two main antigens in lipoprotein structure: antigen $\mathrm{A}$ (antigen 5) and antigen $\mathrm{B} .{ }^{4}$ The host defends himself by mediating cellular and humoral (mainly immunoglobulin G) mechanisms along with the complement activation against these antigens. Among these, the humoral response plays the major role in preventing the parasitic infection. ${ }^{5}$ Wakelin ${ }^{6}$ has shown that survival with Echinococcus granulosus is increased in genetically low antibody responder individuals. However, the correlation of the cyst diameter and quantitative immune response of the host appears yet to be defined.

There is no universally accepted size to define a pulmonary hydatid cyst as "giant." In an endemic 


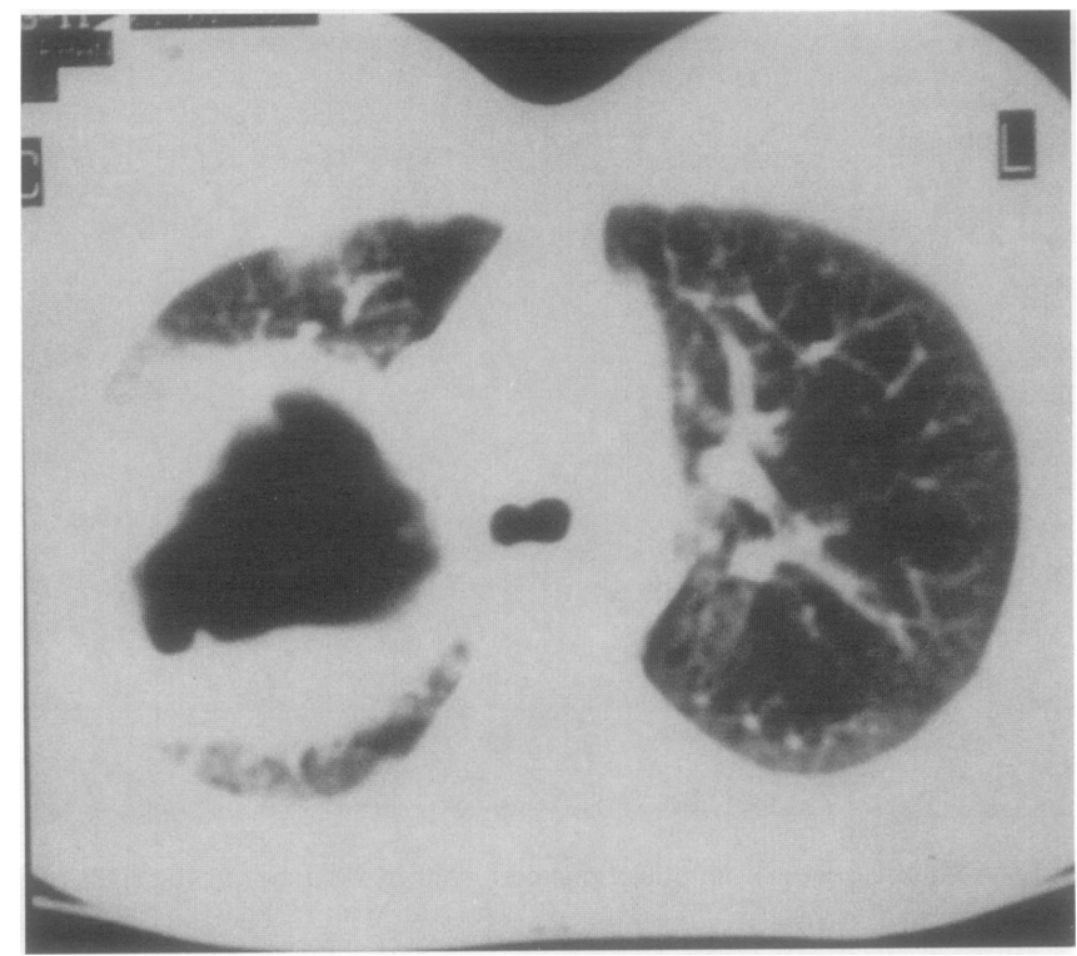

Fig. 3. CT appearance of a complicated giant hydatid cyst of the right lung.

Table II. Operative techniques, complicated/uncomplicated status of the cysts and their correlations with postoperative complications

\begin{tabular}{|c|c|c|c|c|c|c|}
\hline \multirow[b]{2}{*}{ Operative techniques } & \multirow[b]{2}{*}{$\begin{array}{c}\text { Patients } \\
(n=47)\end{array}$} & \multicolumn{2}{|c|}{ Hydatid cysts $(n=50)$} & \multicolumn{3}{|c|}{ Complications $(n=9)$} \\
\hline & & $\begin{array}{c}\text { Complicated } \\
(n=27)\end{array}$ & $\begin{array}{l}\text { Uncomplicated } \\
\quad(n=23)\end{array}$ & $\begin{array}{l}\text { Prolonged } \\
\text { air leak }\end{array}$ & Empyema & Pneumonia \\
\hline Cystotomy + capitonnage & 31 & 19 & 12 & 3 & 2 & \\
\hline Pericystectomy + capitonnage & 6 & 1 & 5 & 1 & 1 & 1 \\
\hline Pericystectomy + closure of bronchial openings & 6 & & 6 & 1 & & \\
\hline Lobectomy & 3 & 6 & & & & \\
\hline Without intervention & $1^{*}$ & 1 & & & & \\
\hline
\end{tabular}

*Patient died at operation before an intervention to the cyst.

country, the size can increase up to two thirds of a hemithorax, ${ }^{7}$ yet an increase to $6 \mathrm{~cm}$ in hydatid disease is rare. ${ }^{8}$ Ten centimeters, the size we have used, seems an appropriate length in that it equals nearly half of a hemithorax of most patients.

Because tissue resistance is one of the most important factors for cyst growth, a giant cyst can more often be expected in young patients whose lung tissue has more elastic properties. Additionally, uninvolved lung of a young patient can be adequate for ventilation with no or minimal symptoms, whereas the same portion of uninvolved parenchyma is not sufficient for ventilation in an older patient. Consequently, late symptoms in a young patient can enhance cyst enlargement. These two phenomena may explain why we have observed that diameter of cysts increased while the patients' ages decreased.

Although recent reports suggest medical therapy with albendazole, ${ }^{9,10}$ surgery is still the best choice for treatment of hydatid disease. Decision-making criteria in selecting operative techniques differs: from one country to another and is closely related to experience with the disease. However, the size of the cyst and the presence of complications are the most commonly accepted criteria for deciding which tech- 
nique should be preferred. ${ }^{11-14}$ Resection, such as a lobectomy, in most instances has been reported in countries where hydatidosis is sporadic. ${ }^{13,14} \mathrm{We}$ have avoided resection unless the lobe was thoroughly destroyed and have used parenchyma-saving procedures in 43 of 47 patients $(91.5 \%)$. Because enucleation of the larger cyst carries an increased possibility of rupture during the separation of the pericystic zone from the laminated membrane, ${ }^{12}$ we have most commonly used needle aspiration. However, we recommend enucleation rather than needle aspiration whenever its risk does not outweigh the advantages.

Postoperative complications occurre in $19.1 \%$ of patients $(n=9)$, a figure that was higher than would be expected after operations for normal-sized cysts. To avoid any bronchial leakage, which resulted in pneumonia in one of our patients, the drainage bronchus of the involved lobe should be temporarily occluded. This is necessary not only for the patients undergoing operation with a single-lumen endotracheal tube, but also for the ones with a malfunctioning double-lumen tube. Nearly all the complications could have been prevented if we had performed a resection; however, complications were treated adequately with the usual approaches in these patients and their lobes were preserved.

In summary, even though hydatid disease commonly occurs in the first three or four decades of life, we found that giant hydatid cysts tend to occur in even younger patients. Considering the good recovery of lung tissue, we advocate that the size of the cyst, at least as a single factor, should not be an indication for resection. Resection cannot be avoided in some patients, but the fact that $91.5 \%$ of the operations in the present study were lung-saving indicates that conservative approaches were as safe as resection. Moreover, most of the complications that occur after a lung-saving operation are correctable, but decreased pulmonary reserve of a resected lung is not.

\section{REFERENCES}

1. Bakir F. Serious complications of hydatid cyst of the lung. Am Rev Respir Dis 1967;96:483-93.

2. Guntz M, Coppo B, Lorimier G, Cornier P. Les kystes hydatiques du foie de revelation tardive (10 a 22 ans) apres traitment chirurgical d'une hydatidose pulmonaire. Problemes physiopathologiques. J Chir Paris 1990;127:375-81.

3. Ramos G, Duque JL, Yuste MG, Heras F, Gallo MJ, Beltran de Heredia M. La rupture intrapleurale du kyste hydatique du poumon. A propos dequinze observations. Ann Chir: Chir Thorac Cardiovasc 1983; 7:114-6.

4. Harrison LJS, Parkhouse RME. Antigens of taeniid cestodes in protection, diagnosis and escape. Curr Trop Microbiol Immunol 1985;120:159-72.

5. Riley EM, Dixon JB, Kelly OF, Cox DA. Immune response to Echinococcosis granulosus: histological and immunocytochemical observations. Ann Trop Med Parasitol 1984;78: 210-3.

6. Wakelin D. Evasion of the immune response: survival within low responder individuals of the host population. Parasitology 1984;88:639-57.

7. Burgos L, Baquerizo A, Munoz W, de Aretxabala X, Solar C, Fonseca L. Experience in the surgical treatment of 331 patients with pulmonary hydatidosis. $J$ Thorac Cardiovasc Surg 1991;102:427-30.

8. Lamy AL, Cameron BH, Le Blane J, et al. Giant hydatid lung cyst in the Canadian northwest: outcome of conservative treatment in three children. J Pediatr Surg 1993;28: 1140-3.

9. Nahmias J, Goldsmith R, Soibelman M, el On J. Three to 7 years follow up after albendazole treatment of 68 patients with cystic echinococcosis (hydatid disease). Ann Trop Med Parasitol 1994;88:295-304.

10. Gil Grande LA, Rodriguez-Caberio F, Prieto JG, et al. Randomized controlled trial of efficacy of albendazole in intraabdominal hydatid disease. Lancet 1993;342:1269-72.

11. Nin Vivo J, Brandolino MV, Pomi JA, Bertullo H, Stefanski H. Surgical management of pleural disease: hydatid pleural disease. In: Deslauriers J, Lacquet LK, editors. 1st ed. St Louis: Mosby, 1990:420-38.

12. Symbas PN, Aletras H. Hydatid disease of the lung. In: Shields WT, editor. General thoracic surgery. 4th ed. Philadelphia: Williams \& Wilkins, 1994:1021-31.

13. Von Sinner W. Pleural complications of hydatid disease (Echinococcus granulosus). Rofo Fortscher Geb Rontgenstr Neuen Bildgeb Verfahr 1990;152:718-22.

14. Moore RD, Urschel JD, Fraser RE, Nakai SS, Geeraert AJ. Cystic hydatid lung disease in northwest Canada. Can J Surg 1994;37:20-2. 